\title{
Control of the hematopoietic stem cell state
}

\author{
Cell Research (2014) 24:3-4. doi:10.1038/cr.2013.139; published online 8 October 2013
}

Several studies have demonstrated the clonal transmission of distinct differentiation and self-renewal properties in hematopoietic stem cells during the regeneration of blood production in transplanted recipients. A recent publication now identifies Vwf expression as a discriminating marker of a hematopoietic stem cell state that is primed for platelet production in response to thrombopoietin, but also subject to developmental and other, as yet undefined, cues.

Our understanding of tissue development, homeostasis and transformation has been guided by studies of the origin and regulation of blood cell formation from a population of self-sustaining multipotent "hematopoietic stem cells (HSCs)". The first definitive evidence for such cells was generated by experiments showing the ability of rare mouse bone marrow cells to produce serially transplantable multi-lineage clones in recipients whose own blood-forming cells had been killed by irradiation [1]. Subsequent studies of hematopoietic cells with different phenotypes showed that distinct populations with different mature cell output potentials can be prospectively isolated. Additional molecular characterization of these purified phenotypes revealed successive changes in their transcriptional programs. Together, these observations have provided strong support for the concept of a hierarchical model of hematopoiesis in which differentiation and self-renewal potential are progressively and coordinately restricted [2]. More recently, it has become possible to track the outputs of large numbers of HSC-derived clones either using trans- plants of highly purified single cells or cells carrying unique DNA barcodes. The results have demonstrated unanticipated heterogeneity in the patterns of differentiation retained through many HSC self-renewal divisions [3]. However, most of these analyses have not examined clonal outputs of platelets or erythrocytes due to the lack of CD45 on these mature cells.

Molecular characterization of HSCenriched cell populations has revealed that these cells express genes associated with megakaryocyte differentiation, including von Willebrand factor (Vwf) $[4,5]$. This observation led Sanjuan-Pla et al. [6] to investigate whether Vwf expression might be a feature of a subset of HSCs with specific functional properties. Using a transgenic Vwf reporter mouse created for this purpose, they found that Vwf expression occurs in phenotypes of cells that are selectively enriched in HSCs with the most durable and/or myeloid cell output capabilities [5, 7-10]. Transcriptome profiling further showed that $\mathrm{Vwf}^{+}$, but not $\mathrm{Vwf}^{-}$, HSCs show upregulated expression of other megakaryocyte lineage genes, but not genes implicated in granulopoietic or lymphoid differentiation programs. Transplantation of purified cells into irradiated mice showed that $\mathrm{Vwf}^{+} \mathrm{HSCs}$ had robust platelet-producing activity in contrast to transplants of Vwf HSCs that generated marginal numbers of these cells. Moreover, this differential pattern of platelet output activity was sustained through a second round of transplantation, supporting the idea that $\mathrm{Vwf}^{+}$HSCs may be transcriptionally primed for megakaryocyte differentiation. Examination of the lineages represented in clonally reconstituted mice showed that some $\mathrm{Vwf}^{+} \mathrm{HSCs}$ produced cells undergoing megakaryocyte differentiation almost exclusively (Figure 1). Intriguingly, most of the Vwf HSC-derived clones produced predominantly lymphoid cells despite a lack of evidence of their being primed to enter the lymphoid lineage. Sequential transplants further showed that $\mathrm{Vwf}^{+}$ HSCs give rise to daughter HSCs of both types $\left(\mathrm{Vwf}^{+}\right.$and $\left.\mathrm{Vwf}^{-}\right)$at high frequency, whereas Vwf HSCs only rarely produced $\mathrm{Vwf}^{+} \mathrm{HSCs}$, a result suggesting a hierarchical parent-progeny relationship between these 2 HSC states. Additional experiments showed that most HSCs in the fetus are $\mathrm{Vwf}^{+}$ and that this proportion then decreases throughout adulthood - findings also consistent with a parent-progeny relationship between $\mathrm{Vwf}^{+}$and $\mathrm{Vwf}^{-} \mathrm{HSCs}$, controlled in part by a developmental mechanism. Investigation of the regulation of $\mathrm{Vwf}^{+} \mathrm{HSCs}$ showed that induction of endogenous TPO can activate the proliferation of initially quiescent $\mathrm{Vwf}^{+}$(but not Vwf) HSCs. Conversely, in the absence of TPO in vivo (achieved by investigating TPO knockout mice), $\mathrm{Vwf}^{+} \mathrm{HSC}$ numbers are substantially reduced.

The identification by Sanjuan-Pla et al. [6] of a new molecular marker that subdivides the adult mouse HSC compartment should facilitate further characterization of different HSC states and their mechanisms of control. The finding that platelet production is a selective feature of $\mathrm{Vwf}^{+} \mathrm{HSCs}$ is of particular interest given the concurrent publication by Yamamoto et al. [11], which similarly suggests that platelet 


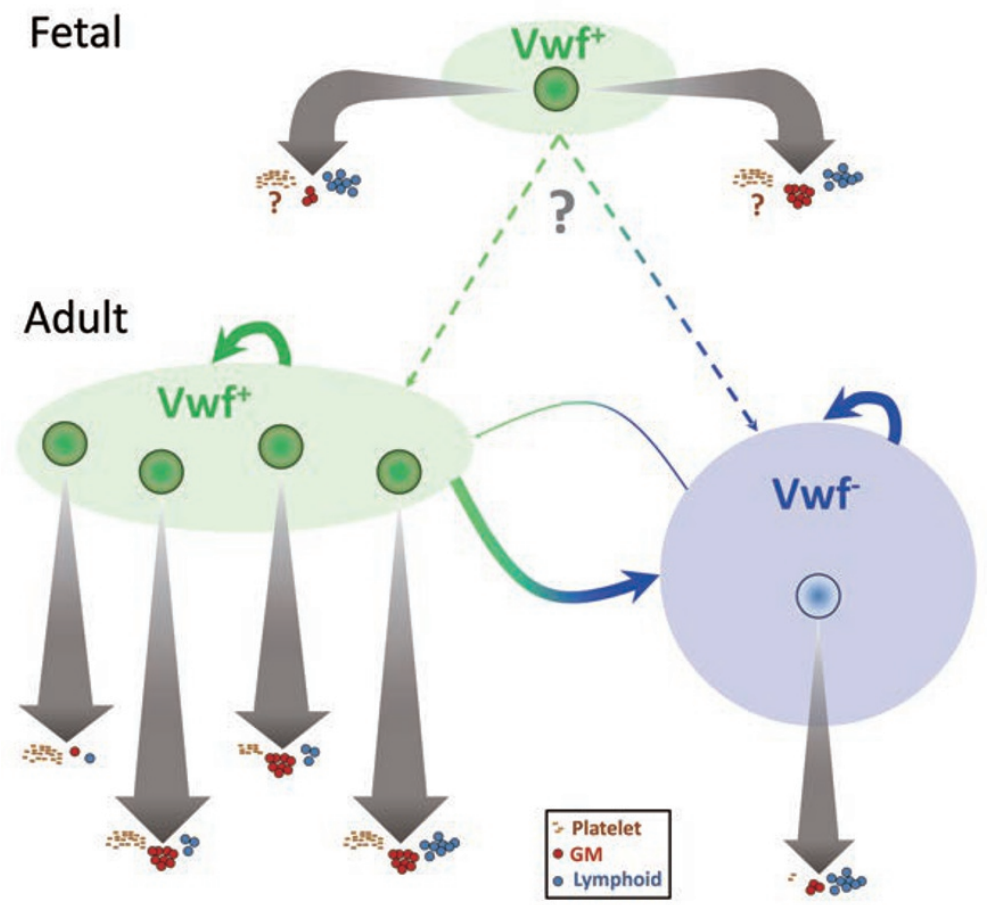

Figure 1 Developmental and hierarchical relationships of Vwf expression in HSCs and the mature cell outputs in clones that they generate.

output is a property of a subset of HSCs with the most durable self-renewal ability. The significance of the prevalent Vwf expression in fetal HSCs is less clear, given previous data showing that many fetal HSCs produce lymphoid cells predominantly [3]. Another point of interest is the apparently similar self-renewal activity found for $\mathrm{Vwf}^{+}$ and Vwf adult HSCs, which contrasts with the different self-renewal properties previously described for HSCs that differ in their myeloid dif- ferentiation potential [3]. Perhaps loss of Vwf expression within the Lin-Sca$1^{+} \mathrm{CKit}^{+} \mathrm{CD} 150^{+} \mathrm{CD} 34^{-}$subset identifies a narrow subset of HSCs that have lost robust myeloid differentiation activity but not durable self-renewal potential. This heterogeneity would be consistent with the recent report that HSCs with different "established" differentiation programs can, nevertheless, modify these on occasion [3]. Such findings are also consistent with the emerging concept that a stem cell state is not as rigidly fixed as historically believed, since it can be re-induced from apparently differentiated cells by exposure to external factors [12]. As such, the epigenetic profiles of the $\mathrm{Vwf}^{+}$and $\mathrm{Vwf}$ HSC states identified by Sanjuan-Pla et al. [6] and the regulatory mechanisms that underpin their ability to interconvert will be of significant future interest.

David JHF Knapp ${ }^{1}$, Connie J Eaves ${ }^{1}$

${ }^{1}$ Terry Fox Laboratory, British Columbia Cancer Agency and University of British Columbia, Vancouver, BC, Canada V5Z 1 L3

Correspondence: Connie J Eaves

E-mail: ceaves@bccrc.ca

\section{References}

1 Fowler JH, Wu AM, Till JE, et al. J Cell Physiol 1967; 69:65-72.

2 Doulatov S, Notta F, Laurenti E, et al. Cell Stem Cell 2012; 10:120-136.

3 Copley MR, Beer PA, Eaves CJ. Cell Stem Cell 2012; 10:690-697.

4 Mansson R, Hultquist A, Luc S, et al. Immunity 2007; 26:407-419.

5 Kent DG, Copley MR, Benz C, et al. Blood 2009; 113:6342-6350.

6 Sanjuan-Pla A, Macaulay IC, Jensen CT, et al. Nature 2013; 502:232-236.

7 Benveniste P, Frelin C, Janmohamed S, et al. Cell Stem Cell 2010; 6:48-58.

8 Morita Y, Ema H, Nakauchi H. J Exp Med 2010; 207:1173-1182.

9 Gekas C, Graf T. Blood 2013; 121:44634472 .

10 Shimazu T, Iida R, Zhang Q, et al. Blood 2012; 119:4889-4897.

11 Yamamoto R, Morita Y, Ooehara J, et al. Cell 2013; 154:1112-1126.

12 Hou P, Li Y, Zhang X, et al. Science 2013; 341:651-654. 